\title{
AS REFORMAS TRABALHISTAS: promessas e impactos na vida de quem trabalha
}

\author{
INTRODUÇÃO
}

\author{
José Dari Krein* (https://orcid.org/0000-0002-4277-2290) \\ Roberto Véras de Oliveira ** (https://orcid.org/0000-0001-7751-6863) \\ Vitor Araújo Filgueiras ${ }^{* * *}$ (https://orcid.org/0000-0002-3284-9178)
}

O objetivo do presente dossiê é analisar e debater as justificativas, o significado e as consequências da implementação das chamadas reformas trabalhistas no Brasil e em algumas das principais experiências internacionais.

Analisando as diferentes reformas, percebe-se um movimento no sentido de ajustar as regras que regem as relações de emprego às tendências do capitalismo contemporâneo, marcado pelos fenômenos da globalização, da reestruturação produtiva e da hegemonia do neoliberalismo. Nesse contexto, tem prevaleci-

\footnotetext{
* Universidade Estadual de Campinas (UNICAMP). Instituto de Economia. Centro de Estudos Sindicais e Economia do Trabalho (CESIT).

Rua Pitagoras, 353, Cidade Universitária Zeferino Vaz. Cep: 13083-857 Campinas - São Paulo - Brasil. darik@ unicamp.br

** Universidade Federal da Paraíba - UFPB. Departamento de Ciências Sociais. Programa de Pós-Graduação em Sociologia. Campus I - Lot. Cidade Universitaria. Cep: 58051-900. João Pessoa - Paraíba - Brasil. roberto.veras.2002@gmail.com

${ }^{* * *}$ Universidade Federal da Bahia. Faculdade de Economia. Praça Treze de Maio, ${ }^{\circ}$ 06. Dois de Julho. Cep: 40060160. Salvador - Bahia - Brasil. fvitor@ufba.br

Os três autores são os coordenadores da Rede de Estudos e Monitoramento Interdisciplinar da Reforma Trabalhista (REMIR) e organizadores do livro "Reforma Trabalhista no Brasil: promessas e realidade" (Campinas, Brasília: Curt Nimuendajú, 2019).
}

do uma dinâmica de crescimento da produção aquém de períodos prévios do capitalismo, relacionada por muitos à chamada financeirização da economia (ou à hegemonia do rentismo). Há referência a uma primazia ou, no mínimo, a uma maior velocidade da expansão dos rendimentos do capital desvinculada da ampliação da produção. Autores de matrizes teóricas distintas tendem a se aproximar, num diagnóstico mais geral do que pode ser chamado de prevalência do rendimento financeiro e patrimonial (Piketty, 2014), do rentismo (Stiglitz, 2012), da dominância das finanças (Chesnais, 2005), ou da acumulação por espoliação (Harvey, 2005). Outros, como Milios e Sotiropoulos (2010), questionam a dominância da finança e do rentismo, afirmando que o capitalismo atual é favorável à valorização do capital como um todo, à imposição de estratégias agressivas de exploração do trabalho.

É parte desse cenário a intensa pressão por mudanças nas normas de proteção social e, em particular, do trabalho, em vários países ao redor do mundo. Trata-se de uma agenda que ganha expressão, ao menos desde os anos 1980, nos países centrais. No Brasil, adquire 
relevância a partir da década de 1990, quando o país adota um novo modelo de desenvolvimento e inserção econômica externa.

Desse modo, disseminaram-se, em escala global, mudanças nos padrões de regulação do trabalho e de proteção social. Os resultados das promessas que embasaram essas iniciativas são, no mínimo, controversos, especialmente no que se refere ao combate ao desemprego. Não obstante isso, especialmente após a crise de 2008, impôs-se uma nova onda de alterações legislativas (Adascalitei, Morano, 2015). Muitos países implementaram alterações legais pontuais, enquanto outros introduziram modificações estruturais que atingem o conjunto da regulação do trabalho. Essas iniciativas mais profundas são comumente identificadas como reformas trabalhistas.

Apesar da existência de sistemas nacionais de regulação do trabalho e de proteção social muito distintos entre os países, chama a atenção o fato de haver grandes similaridades nas reformas, tanto no conteúdo quanto nas justificativas apresentadas. Em geral, elas visam a: 1) ampliar a adoção de contratos atípicos e rebaixar direitos do contrato padrão; 2) flexibilizar a utilização do tempo de trabalho; 3) alterar as regras de remuneração do trabalho, especialmente em relação às formas de paF. gamento (mais variáveis) e à política do salário . mínimo; 4) fragilizar as regras de segurança e $\stackrel{\dot{8}}{\stackrel{8}{1}}$ saúde do trabalho; 5) enfraquecer a atuação pública na fiscalização do respeito à legislação trabalhista; 6) descentralizar a definição das normas e redefinir o papel dos sindicatos. Em síntese, a tendência é a busca de um padrão de regulação do trabalho menos protetivo, propiciando maior liberdade de determinação, pelo empregador, das condições de contratação, uso e remuneração da força de trabalho.

As justificativas aparentes das reformas trabalhistas oscilam. Em alguns casos, argumenta-se abertamente pela diminuição de direitos dos trabalhadores. Entretanto, mais frequentemente, não se fala em reduzir direitos, mas em tornar a regulação do trabalho "mais flexível”. Com isso, abstrai-se, intencionalmente, que o direito do trabalho é, por definição, sempre flexível "para cima", o que significa que trabalhadores, empregadores e suas representações podem realizar quaisquer acordos entre si, desde que sejam mais benéficos aos empregados do que o mínimo previsto em lei. Destarte, a flexibilização almejada é, necessariamente, a permissão para subtrair direitos. $\mathrm{O}$ alicerce que legitima o argumento da flexibilização e as próprias reformas trabalhistas é a ideia de que elas são condição necessária para reduzir o desemprego, a partir de perspectivas mais radicais (Mankiw, 2005) ou ponderadas (OECD, 2018).

No Brasil, nos anos 1990 e 2000, foram introduzidas algumas mudanças na legislação, sem, contudo, haver alterações estruturais no marco regulatório. Foi com a aprovação das Lei 13.467/2017, em julho de 2017, que o país se inseriu no rol dos países que implementaram reformas trabalhistas nas últimas décadas. Seus defensores aproveitaram a crise econômica desencadeada em 2015 para impor e convencer o Congresso Nacional de que tal medida combateria o crescente desemprego, como evidencia o Parecer que consolidou a reforma:

\footnotetext{
Escudada no mantra da proteção do emprego, o que vemos, na maioria das vezes, é a legislação trabalhista como geradora de injustiças, estimulando o desemprego e a informalidade. Temos, assim, plena convicção de que essa reforma contribuirá para gerar mais empregos formais e para movimentar a economia (Parecer da Reforma, 2017, p. 20).
}

Chama a atenção o fato de que esse argumento prevaleceu, mesmo tendo havido, entre 2004 e 2014, forte criação de empregos e formalização dos contratos de trabalho sem que tivesse ocorrido uma reforma. Alguns estudos evidenciaram, inclusive, o quanto a existência de um arcabouço legal e institucional, juntamente com políticas de estímulo ao consumo, contribuíram para a melhoria dos indicadores de emprego, formalização e renda (Baltar; Souen; Caldas, 2017; Bastos, 2017; Carvalho, 2018). A reforma trabalhista implementada no Brasil é muito ampla, atingindo mais de uma 
centena de artigos da legislação, especialmente da CLT, contemplando todos os aspectos das relações de trabalho, as instituições públicas e os sindicatos. Nem as mais ambiciosas reivindicações empresariais previam, anos antes, uma mudança legislativa tão profunda (CNI, 2012). As medidas aprovadas podem, inclusive, afetar o sistema de seguridade social, pois, por um lado, tendem a dificultar o preenchimento dos requisitos para os trabalhadores terem acesso aos benefícios. Por outro lado, tendem a fragilizar uma das principais fontes de financiamento da Previdência, pois promovem contratos mais precários e estimulam formas de remuneração sem caráter salarial. Portanto, é uma reforma com potencial de afetar todo o sistema protetivo da sociedade brasileira.

Este dossiê abarca reflexões de diferentes grupos de pesquisa que integram a Rede de Estudos e Monitoramento Interdisciplinar da Reforma Trabalhista (REMIR), que vem desenvolvendo investigações empíricas e reflexões teóricas visando a contribuir para colocar o significado e os impactos da reforma no debate nacional e internacional.

O dossiê contém sete artigos que contemplam a análise de experiências internacionais e os principais aspectos das mudanças nas normas de proteção ao trabalho (formas de contratação, remuneração, jornada de trabalho, segurança e saúde no trabalho, organização do trabalho), no papel e na forma de funcionamento das instituições públicas e do sindicalismo. Os estudos percorrem recortes regionais e setoriais diversos, buscando apreender como os "cardápios" oferecidos pelas reformas vêm sendo acionados, tendo em conta as diversas estratégias empresariais e as resistências, em cada caso.

O primeiro artigo, "Os impactos jurídicos, econômicos e sociais das reformas trabalhistas", escrito por Vitor Filgueiras, Uallace Lima e Ilan Fonseca, analisa os impactos das reformas em seis países, comparando-os com o caso brasileiro. Os autores identificam, a despeito das particularidades de cada país e das mudanças legais em cada um deles não serem unívocas, as seguintes semelhanças em quase todas as reformas: 1) no campo jurídico, tendência ao recrudescimento da mercadorização da força de trabalho, reduzindo-se a proteção aos trabalhadores; 2) no campo econômico, as promessas das reformas não se confirmam, ou seus impactos são controversos, e sua generalização é limitada; 3) os impactos sociais são parecidos e generalizáveis, e implicam piora na venda e uso da força de trabalho na medida da efetividade das reformas.

A seguir, insere-se o artigo de Jose Dari Krein, Andréia Galvão, Bárbara Castro e Marilane Teixeira, "Reforma trabalhista: precarização, sindicalismo e gênero". Os autores argumentam que a reforma, no intuito de intensificar a ofensiva sobre os direitos sociais e trabalhistas, está fragilizando os sindicatos. Apontam também como a reforma interfere na capacidade de negociação dos sindicatos, dentre outras razões, pela possibilidade de formas de negociação individual e da rescisão contratual sem intermediação sindical, além de afetar as finanças das entidades. $\mathrm{O}$ artigo problematiza a maneira como a reforma repercute sobre as negociações coletivas e a ação dos sindicatos, com ênfase na precarização do trabalho feminino.

Em "A Reforma Trabalhista e suas implicações para o Nordeste: primeiras reflexões", Roberto Véras, Mário Ladosky e Maurício Rombaldi discutem as implicações da Reforma Trabalhista no Nordeste, com foco nos setores automobilístico e de tecnologia da informação, em Pernambuco, e da construção civil, na Paraíba. Com isso, eles avaliam se a nova legislação tende a agravar as desigualdades sociais que marcam o Brasil e, ainda mais, o Nordeste.

No artigo seguinte, Graça Druck, Renata Dutra e Selma de Jesus abordam a reforma trabalhista a partir do contexto histórico que permitiu sua edição. Em "A contrarreforma neoliberal e a terceirização: a precarização como regra”, elas lançam um olhar específico sobre a precarização do trabalho engendrada pela terceirização, que é confrontado com os primeiros 
dados a respeito do mercado de trabalho após a reforma, permitindo que observem, no novo marco legal, a legitimação, o aprofundamento, e a tendência à generalização dos indicadores de precarização outrora aferidos em contextos específicos de contratação terceirizada. Apontam também para as perspectivas de resistência em relação à regulação mercantilizada do trabalho instaurada pela reforma trabalhista.

Christian Azaïs e Adalberto Cardoso apresentam o artigo "Reformas trabalhistas e seus mercados. Uma comparação Brasil - França”. Eles apontam que as reformas se enquadram na tendência mundial de recrudescimento da individualização das formas de inserção no trabalho, justamente em um contexto de celebração do coletivo, do trabalho em equipe, da cooperação no âmbito das organizações. As reformas, no Brasil e na França, engendram um corte temporal que transforma o mercado de trabalho num "laboratório" que poderá isolar os feitos das novas regras sobre sua dinâmica e funcionamento. Nessa perspectiva, os autores questionam se já é possível detectar impactos relevantes das reformas na dinâmica dos mercados de trabalho, e se elas vêm cumprindo suas promessas, particularmente, no que concerne às partes mais vulneráveis da população.

Em "Trabalho digital, emprego e flexibili2. zação: a reforma trabalhista e o aprofundamenN to da precariedade", Maria Aparecida Bridi e Jacob Lima questionam em que medida a reforma trabalhista brasileira favorece a chamada "uberização" do trabalho. Para eles, "a precariedade é constituinte desses 'novos' trabalhos que surgem num contexto de flexibilidade e inovações $\therefore$ tecnológicas, no qual a internet pontifica, mesclando tempo e espaço, embaralhando questões i constituintes do próprio valor trabalho, do tempo e espaço, do material e imaterial e do próprio conceito de empresa”. Nesse processo, o capitalismo busca transferir aos trabalhadores os ônus da flexibilidade e do risco.

Fecha o dossiê o artigo "Mudanças na legislação trabalhista, ação sindical e estratégias de empresas multinacionais", de José Ricardo
Ramalho, Rodrigo Pereira dos Santos e Iram Jácome Rodrigues. Eles analisam a relação entre os interesses das Empresas Multinacionais (EMNs) e as alterações recentes na legislação brasileira do trabalho, a partir do caso da indústria automotiva. $\mathrm{O}$ artigo identifica de que forma a redução da proteção ao trabalho e o aumento da instabilidade no emprego têm sido utilizados pelas empresas para ampliar o controle sobre os trabalhadores e enfraquecer suas entidades de representação.

Em qualquer conjuntura, mas particularmente na atual, urge racionalizar os debates e disputas que envolvem a implementação de políticas públicas. Sem pretender disfarçar as orientações valorativas que todos temos, precisamos basear nossas posições em evidências para nos aproximar de alguma compatibilização entre fins que almejamos e meios que defendemos para alcançá-los. Ou seja, não podemos apresentar pressupostos como se fossem conclusões.

O presente dossiê trata de um tema que atinge diretamente a maioria das pessoas que trabalham no mundo. A despeito das alusões precipitadas em sentido contrário, o trabalho assalariado (objeto da regulação do direito do trabalho) é majoritário, e tem crescido nas últimas décadas, em todas as regiões do planeta. No caso do Brasil, mesmo com o destaque dado a outras formas aparentemente alternativas de organização do trabalho, seu conteúdo não difere, essencialmente, do assalariamento. Pelo contrário, está-se diante, justamente, de um processo de disputa pela regulação do trabalho subordinado, no qual a própria designação da relação joga papel importante (Filgueiras; Cavalcante, 2017).

Se é pouco controversa a constatação de que, após a reforma, desemprego e informalidade não foram reduzidos, os nexos causais para explicar esse fracasso são pouco, mal ou nada debatidos nos meios de comunicação, particularmente na grande mídia, que se restringe a repetir o senso comum sobre a relação entre direito do trabalho e emprego, inspirado na teoria econômica dominante e suas ramificações. Diante do não cumprimento dos ob- 
jetivos declarados da reforma, ao invés de se propor um debate profundo sobre a regulação do trabalho no país, adota-se a estratégia de afirmar que é preciso mais tempo para que a reforma atinja suas metas, ou de que é necessário cortar ainda mais direitos (com ou sem o eufemismo da "flexibilização") para alcançar tais promessas. Esperamos que este dossiê contribua para chamar a atenção e subsidiar debates mais qualificados sobre as normas de proteção ao trabalho em nosso país.

Recebido para publicação em 19 de agosto de 2019 Aceito em 20 de agosto de 2019

\section{REFERÊNCIAS}

ADASCALITEI, D.; MORANO, C. P. Labour market reforms since the crisis: drivers and consequences. Geneve: OIT, 2015. (Research Department Working Paper, $\mathrm{n}^{\circ} 5$ ).

BALTAR, P. E.; SOUEN, J. A.; CALDAS, G. S. Emprego e distribuição da renda. Campinas: Instituto de Economia, maio 2017. (Texto discussão, $n^{\circ} 298$ ).

BASTOS, P. P. Z. Macroeconomia e mercado de trabalho: as principais teorias e o Brasil contemporâneo. Revista Ciências do Trabalho, São Paulo, n. 7, p. 51-107, 2017.

CARVALHO, L. Valsa brasileira: do boom ao caos econômico. São Paulo: Todavia, 2018.
CARVALHO, L.; RUGITSKY, F. Growth and distribution in Brazil the 21st century: revisiting the wage-led versus profit-led debate. São Paulo: Department of Economics, FEA-USP. 2015. (Working Paper Series, $n^{\circ}$ 201525). Disponível em: http://www.repec.eae.fea.usp.br/ documentos/Carvalho_Rugitsky_25WP.pdf. Acesso em: 25.05 .2019

CHESNAIS, F. A finança mundializada - raízes sociais e políticas, configuração, consequências. São Paulo: Boitempo, 2005.

CNI. 101 propostas para modernização trabalhista. Brasília: CNI, 2012

FILGUEIRAS, V.; CAVALCANTE, S. What has changed: a new Farewell to the Working Class? 5th CONFERENCE OF THE REGULATING FOR DECENT WORK NETWORK. ILO: Geneva, July 2017.

HARVEY, D. O novo imperialismo. $2^{\text {a }}$ ed. São Paulo: Loyola, 2005.

MANKIW, G. Introdução a economia. Rio de Janeiro: Campos, 2005.

MILIOS, J.; SOTIROPOULOS, D. P. Financeirização: disciplina do mercado ou disciplina do capital? Conference: understanding the economic crisis: the contribution of marxisant approaches. Atenas: University of Piraeus, 2010.

OECD. Relatórios econômicos OCDE: Brasil (resumo). 2018

PARECER DA REFORMA. Comissão Especial destinada a proferir parecer ao Projeto de Lei $n^{\circ} 6.787$, de 2016, do Poder Executivo que "altera o Decreto-Lei $n^{\circ}$ 5.452, de $1^{\circ}$ de maio de 1943". Brasília: Câmara dos Deputados, 2017. Disponível em https://www.camara.leg.br/ proposicoesWeb/prop_mostrarintegra?codteor $=1544961$. Acesso em: 20.05.2019

PIKETTY, T. O capital no século XXI. Rio de Janeiro: Intrínseca, 2014.

STIGLITZ, J. E. The price of inequality. Nova Iorque: W.W. Norton \& Company, 2012.

José Dari Krein - Professor do Instituto de Economia e pesquisador do CESIT (Centro de Estudos Sindicais e Economia do Trabalho). Presidente da ABET (2007-2009). Pesquisa relações e mercado de trabalho, sindicalismo e negociações coletivas. Coordenação da REMIR (Rede de Estudo e Monitoramento Interdisciplinar da Reforma Trabalhistas, em 2019). Publicações recentes: The CUT's Experience during the Workers' Party Governments in Brazil (2003-2016). Global Labour Journal, v. 9, p. 199-214, 2018; Flexibilização das relações de trabalho: insegurança para os trabalhadores. Revista do Tribunal Regional do Trabalho da 15. Região, v. 1, p. 41-66, 2018; Aspectos para discutir o significado da contrarreforma trabalhista e suas consequências. Intervozes, v. 3, p. 112-116, 2018.

Roberto Véras de Oliveira - Doutor em Sociologia pela USP. Pós-Doutorado pela University of California - Los Angeles. Bolsista de Produtividade do CNPq. Professor Associado, vinculado ao Departamento de Ciências Sociais e ao Programa de Pós-Graduação em Sociologia da Universidade Federal da Paraíba UFPB. Publicou Sindicalismo e democracia no Brasil: do novo sindicalismo ao sindicato cidadão. São Paulo: Annablume Editora, 2011. v. 1. 394p.

Vitor Araújo Filgueiras - Professor de Economia da Universidade Federal da Bahia (UFBA). Pósdoutorado em Economia pela Universidade Estadual de Campinas (UNICAMP). Estágio de Pós-doutorado (SOAS, Universidade de Londres). Doutorado em Ciências Sociais pela UFBA. Mestrado em Ciência Política pela UNICAMP. Graduação em Economia pela UFBA. Secretário da Associação Brasileira de Estudos do Trabalho (ABET) (2018-2019). Foi Auditor Fiscal do Ministério do Trabalho entre 2007 e 2017. Publicações recentes: A Indústria 4.0 e o debate acerca dos seus impactos sobre o emprego. Princípios (São Paulo), v. 1, p. 1, 2017; Riscos ocupacionais e invisibilização do adoecimento no tele atendimento. Revista Baiana da Inspeção do Trabalho, v. 1, p. 164, 2016; Regulação da terceirização e estratégias empresariais: o aprofundamento da lógica desse instrumento de gestão da força de trabalho. Cadernos do CEAS, v. 239, p. 742-770, 2016. 